\title{
The relationship of excessive energy deficit with milk somatic cell score and clinical mastitis
}

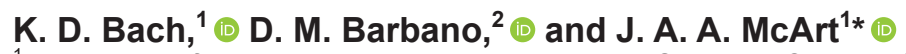 \\ ${ }^{1}$ Department of Population Medicine and Diagnostic Sciences, College of Veterinary Medicine, Cornell University, Ithaca, NY 14853 \\ ${ }^{2}$ Department of Food Science, College of Agriculture and Life Sciences, Cornell University, Ithaca, NY 14853
}

\begin{abstract}
Periparturient cows go through a period of immune suppression often marked by immune cell dysfunction. Further exacerbation of this dysfunction through earlylactation excessive energy deficit (EED) has been associated with increased susceptibility to infectious conditions such as mastitis. Our objective was to explore the association of milk somatic cell score (SCS) and clinical mastitis (CM) diagnosis in cows identified with EED, diagnosed using each of the following: blood and milk $\beta$-hydroxybutyrate (BHB), milk predicted blood nonesterified fatty acid (mpbNEFA) concentrations, or milk de novo fatty acid (FA) relative percentages (rel $\%$ ). We analyzed data collected from 396 multiparous Holstein cows from 2 New York farms in a prospective cohort study. Coccygeal vessel blood samples and composite milk samples were collected twice weekly from 3 to 18 days in milk (DIM) for a total of 4 time points per cow (T1, T2, T3, T4). Blood was analyzed using a hand-held meter, and milk was analyzed using Fourier-transform mid-infrared spectrometry for milk BHB and mpbNEFA concentrations, milk de novo FA rel \%, and somatic cell count. Excessive energy deficit was diagnosed as blood BHB $\geq 1.2 \mathrm{mmol} / \mathrm{L}$, milk BHB $\geq 0.14 \mathrm{mmol} / \mathrm{L}, \mathrm{mpbNEFA} \geq 0.55 \mathrm{mmol} / \mathrm{L}$, or de novo $\mathrm{FA} \leq 22.7$ rel $\%$, depending on the model. Clinical mastitis cultures were collected from 4 to 60 DIM by on-farm personnel. Incidence of hyperketonemia as determined by blood BHB was $13.4 \%$, and incidence of $\mathrm{CM}$ was $23.9 \%$. Separate repeated-measures ANOVA models were developed for each EED diagnostic analyte for parity groups 2,3 , and $\geq 4$ to assess differences in SCS; $t$-test analyses were similarly used to assess the association of each diagnostic analyte with $\mathrm{CM}$ at each time point. For all diagnostic analytes, apart from milk BHB, cows diagnosed with EED tended to have lower SCS than their non-EED counterparts. This was
\end{abstract}

Received February 26, 2020.

Accepted August 26, 2020.

*Corresponding author: jmcart@cornell.edu especially apparent at $\mathrm{T} 1$ for all parity groups, and at T2, T3, and T4 for blood BHB and mpbNEFA. For EED diagnosis via mpbNEFA, mean SCS were lower in parity $\geq 4$, with a difference in mean SCS between EED and non-EED animals of 0.7 SCS units, equating to a somatic cell count in EED animals approaching half that of non-EED $(\mathrm{EED}=67,000$ cells $/ \mathrm{mL}$, non-EED $=107,000 \mathrm{cell} / \mathrm{mL}$ ). No important relationships were observed between $\mathrm{CM}$ diagnosis and blood BHB, milk BHB, or mpbNEFA. For de novo FA rel \%, reductions in this analyte were noted before CM diagnosis at all time points. Although the relationship between EED and CM is still unclear, our findings suggest that cows in EED, diagnosed using blood BHB or mpbNEFA during the first 18 DIM, have a tendency toward lower SCS compared with their non-EED counterparts.

Key words: energy deficit, FTIR, somatic cells, mastitis, dairy cows

\section{INTRODUCTION}

During the transition period, cows enter a period of energy deficit due to increased energy requirements of lactation coupled with decreases in dry matter intake (Bauman and Currie, 1980; Baird, 1982; Herdt, 2000). Normal adaptation to this deficit results in breakdown of fat stores into nonesterified fatty acids (NEFA), which, among other potential pathways within the liver, are partially oxidized to form ketone bodies, including BHB (Palmquist et al., 1969; Herdt, 2000). These substrates are then utilized by the peripheral tissues as alternative energy sources. However, in cases of excessive energy deficit (EED), high levels of circulating NEFA and BHB, known as hyperketonemia (HYK), have been associated with negative downstream health and production outcomes, including increased risk of displaced abomasum (DA), metritis, and leaving the herd, as well as decreases in early lactational milk yield and reproductive success (Ospina et al., 2010; Chapinal et al., 2011; McArt et al., 2012).

Concurrently, a natural suppression of immune function occurs during the transition period, furthering 
the risk of infectious disease development in postpartum cows (Kehrli et al., 1989; Hammon et al., 2006). Furthermore, the role that EED plays in the immune dysfunction seen during the postpartum period appears to be an important one. Numerous in vitro studies have shown that immune cells co-incubated with BHB have altered function, including diminished polymorphonuclear cell chemotaxis, reduced phagocytosis of milk neutrophils and macrophages, and depressed leukocyte respiratory burst activity (Kluciński et al., 1988; Hoeben et al., 1997; Suriyasathaporn et al., 1999). Additionally, large-scale epidemiological studies and meta-analyses have found associations between cows with HYK and an increased risk of infectious disease development, including mastitis (Erb and Grohn, 1988; Oltenacu and Ekesbo, 1994; Raboisson et al., 2014).

Recently, new methods of identifying EED have become available utilizing partial least squares (PLS) regression estimates of milk and blood constituents using Fourier-transform mid-infrared (FTIR) analysis of milk. Because EED is a multifactorial disease process putting animals at risk of many adverse events (Sordillo, 2016), only one of which is HYK, multiple studies have examined FITR methods for diagnosing EED, using not only milk BHB and milk predicted blood NEFA (mpbNEFA), but also milk de novo fatty acid (FA) relative percentages (rel \%; Santschi et al., 2016; Bach et al., 2019; Luke et al., 2019). However, few of these studies have looked at the relationship between alterations in predicted constituents and mammary health, and those that have done so were conducted during monthly DHIA testing (Santschi et al., 2016).

We hypothesized that dysfunction of the immune system, as a consequence of EED, would result in a reduction in somatic cells within the mammary gland. Furthermore, because animals with very low SCC have an increased risk of developing clinical mastitis (CM; Schukken et al., 1999; Beaudeau et al., 2002), we also hypothesized that cows with EED would have an increased risk of CM compared with their non-EED counterparts. Therefore, our objectives were to explore the relationship between EED diagnosis, using each of the diagnostic analytes blood BHB, milk BHB, mpbNEFA, or milk de novo FA rel \%, with SCS and CM diagnosis.

\section{MATERIALS AND METHODS}

\section{Study Population}

Data were collected from 2 dairy farms (farms A and B) in New York from July through November 2016. Farm selection criteria were as follows: milk at least 1,000 cows, have headlocks in fresh cow pens, use the farm management program DairyComp 305 (Valley
Agricultural Software, Tulare, CA), and be willing to participate in the proposed testing protocol. During the study period, farm A milked 1,060 cows 3 times/d and averaged $43 \mathrm{~kg} / \mathrm{d}$ of milk per cow, and farm B milked 1,100 cows 3 times/d and averaged $41 \mathrm{~kg} / \mathrm{d}$ of milk per cow. Both herds housed cows in freestall barns with concrete floors and fed a TMR. Farm A bedded with sand, and farm B used mattresses and recycled paper pulp.

\section{Data Collection and Study Design}

Approval for all animal procedures was granted by the Cornell University Institutional Animal Care and Use Committee (protocol 2015-0123; Ithaca, NY). All farms signed a consent form agreeing to the proposed testing protocol. Sample size calculations for the study estimated enrollment at 580 cows, using assumed incidences of $40 \%$ HYK (10\% CM in non-HYK cows and $18 \%$ CM in HYK cows), a type I error risk of $5 \%$, and a type II error risk of $20 \%$.

A full description of sample collection for this prospective cohort study has been published previously (Bach et al., 2019). Briefly, enrollment began at calving, with all multiparous cows eligible for enrollment. Composite milk samples for mastitis detection at freshening (fresh cultures) were collected between 1 and 3 DIM by trained farm personnel, and cows found culture-positive during this period were not included in analysis (farm $\mathrm{A}: \mathrm{n}=15$; farm $\mathrm{B}: \mathrm{n}=42$ ). At any point $\geq 4$ DIM, if cows were identified as having CM in any quarter (i.e., abnormal milk; udder appearing swollen, red, and warm to the touch), a sample was collected by trained farm personnel for CM diagnosis. All milk sample collection occurred following normal milk preparation, including a dry wipe, dipping with iodine-based teat dip, stripping, and an additional dry wipe. Teat ends were sanitized with $70 \%$ isopropyl alcohol, and the first few streams of milk were discarded before sample collection. Samples were refrigerated until aerobic culture analysis by Quality Milk Production Services (Cornell University, Ithaca, NY), and culturing occurred twice weekly (Mondays and Thursdays) for farm A and $5 \mathrm{~d} /$ wk for farm B, as per Quality Milk Production Services standard operating procedures.

Due to compliance limitations, approximately $35 \%$ of cows did not have a composite milk sample for mastitis detection at freshening collected within the 1 to 3 DIM period (farm $\mathrm{A}: \mathrm{n}=128$; farm $\mathrm{B}: \mathrm{n}=26$ ). However, many of these animals had composite samples taken between 4 and 9 DIM $(\mathrm{n}=141)$. Because we had no way of determining whether these samples were meant for mastitis detection at freshening or for CM diagnosis during lactation, the following assumptions were made 
for all cows without a composite milk sample collected between 1 and 3 DIM but with a composite milk sample collected between 4 and 9 DIM: culture-negative results were recorded as samples collected for mastitis detection at freshening, and cows remained in the data set for analysis $(\mathrm{n}=105)$. Culture-positive results were recorded as samples collected for $\mathrm{CM}$ diagnosis and assumed not to have mastitis upon entering lactation (n $=32$ ).

Blood sampling and composite milk sampling for constituent analysis occurred twice weekly for each farm from 3 to 18 DIM: for farm A on Mondays and Thursdays, and for farm B on Tuesdays and Fridays. Given this testing scheme, each cow was sampled 4 times. Time points were as follows: 3 to 7 DIM (T1), 6 to 11 DIM (T2), 10 to 14 DIM (T3), and 13 to 18 DIM (T4). All milk samples for FTIR analysis were collected during the morning milking. Blood samples were collected during fresh cow lock-up, which was immediately before milking for farm A and immediately after milking for farm B. All blood samples were taken within $1 \mathrm{~h}$ of milking.

Milk samples were collected using International Committee on Animal Recordings-approved proportional milk samplers. Immediately after collection, samples were submerged in crushed ice until submission to the Department of Food Science at Cornell University (Ithaca, NY) for milk composition analysis.

For blood sampling, heparinized whole blood samples were collected from a coccygeal vessel. Blood samples remained at room temperature until testing for HYK using a Nova Vet meter (Nova Biomedical, Waltham, MA), which occurred within $4 \mathrm{~h}$ of collection (Iwersen et al., 2013; Megahed et al., 2017). Samples with BHB concentration $\geq 1.2 \mathrm{mmol} / \mathrm{L}$ were considered EED positive.

Calving, health, and production data were extracted from farm computer records weekly. Disease event data were recorded by on-farm personnel using standard disease definition protocols discussed before start of the trial. Body condition score (Ferguson et al., 1994) and locomotion score (Sprecher et al., 1997), both on a 5-point scale, were assessed by the first author on the first day of blood sampling for each animal (3 to 7 DIM). Daily milk weights were averaged on a weekly basis to estimate average weekly milk yield $(\mathrm{kg} / \mathrm{d})$ over each of the 3 wk of sample collection (van Hoeij et al., 2018).

\section{Milk Composition Analysis}

Milk fat, true protein, and anhydrous lactose content were determined using a FTIR spectrophotometer
(Lactoscope model FTA, Delta Instruments, Drachten, the Netherlands) at the Department of Food Science at Cornell University (Ithaca, NY) as described previously (Bach et al., 2019). Milk SCC was measured using a fluorometric flow cytometry method using DAPI (4',6-diamidino-2-phenylindole) as the staining dye (Delta Instruments, SomaSmart). Calibration of milk SCC was performed using calibration samples from the USDA Federal Milk Markets with reference values established using the direct microscopic somatic cell count method (Fitts and Laird, 2004). To aid in analysis, SCC was converted to SCS using the following equation: $\mathrm{SCS}=\log _{2}(\mathrm{SCC} / 100,000)+3$ (Ali and Shook, 1980).

De novo, mixed-origin, and preformed milk FA were measured directly as grams per $100 \mathrm{~g}$ of milk by FTIR using the PLS prediction models described by Woolpert et al. (2016). De novo FA rel \% were determined by calculating the proportion of de novo FA (g/100 g of milk) compared with total milk FA (sum of de novo, mixedorigin, and preformed FA; g/100 g of milk). Gas-liquid chromatography reference chemistry for calibration of milk FA estimates was as described by Wojciechowski and Barbano (2016). The milk FA calibration sample set was the same 14-sample set that was used for calibration of the main milk components. The calibration concentration ranges for de novo, mixed-origin, and preformed milk FA were as follows: de novo 0.05 to 1.4 $\mathrm{g} / 100 \mathrm{~g}$ milk; mixed-origin 0.08 to $2.2 \mathrm{~g} / 100 \mathrm{~g}$ milk; and preformed 0.06 to $1.9 \mathrm{~g} / 100 \mathrm{~g}$ milk.

Milk BHB and mpbNEFA concentrations were measured by FTIR using PLS regression models developed in collaboration with Delta Instruments (parameter numbers 1601 and 1603, respectively). Conversion of mpbNEFA from $\mu \mathrm{Eq} / \mathrm{L}$ (units predicted by PLS model) to $\mathrm{mmol} / \mathrm{L}$ was performed via the following calculation: $(\mu \mathrm{Eq} / \mathrm{L} \times 0.001 \mathrm{mEq} / 1 \mu \mathrm{Eq}) \times 1=\mathrm{mmol} / \mathrm{L}$.

\section{Milk Predicted Blood NEFA Prediction Model Development and Validation}

Data for model development were collected from the Cornell University Ruminant Center (Harford, NY) and the William H. Miner Agricultural Institute (Chazy, NY) from May to September 2011, in studies separate from our reported study. Once-weekly blood and milk samples were collected from individual Holstein cows during the first 9 wk of lactation for use in development of the PLS model to predict blood NEFA from mid-infrared milk spectra. Blood samples were collected within $\pm 8 \mathrm{~h}$ of the milk collection. Blood plasma was analyzed for NEFA using commercially available kits (NEFA: HR Series NEFA-HR, Wako 
Diagnostics, Mountain View, CA) on a Roche Cobas 6000 series, c501 Clinical Chemistry Automated Analyzer (Roche Diagnostics, Indianapolis, IN) at the New York State Animal Health Diagnostic Center (Ithaca, NY). A FTIR milk analyzer (Model FTA Lactoscope, Delta Instruments) was used to collect a mean infrared spectrum for each milk sample by averaging 16 scans at $8 \mathrm{~cm}^{-1}$ spectral resolution using an ABB Bomem (Montreal, Canada) optical system that operated in the Delta Lactoscope.

Modeling was performed using the PLSplus/IQ portion of Grams/32 software (ThermoGalactic, Salem, $\mathrm{NH})$ statistics for the mpbNEFA measurement with a one-out cross modeling. The PLS model for mpbNEFA was calculated using the spectral ranges $(3,000$ to $2,750,1,800$ to 1,700 , and 1,580 to $\left.1,000 \mathrm{~cm}^{-1}\right)$, applying mean centering of the data and 2-point baseline correction relative to average absorbance calculated over wavelength ranges of 2,650 to $2,550 \mathrm{~cm}^{-1}$ and 1,260 to $1,200 \mathrm{~cm}^{-1}$. Cross validation (cyclic leaving out 1 sample at a time) was applied for determining the number of factors used for the model. Spectral and concentration outlier samples were identified based on Mahalanobis distances and removed from the data set, and then the PLS modeling was repeated with outliers removed.

An external validation of the mpbNEFA model performance was done on a subpopulation of 174 individual, paired milk and plasma samples collected from the current study (i.e., not used for development of the prediction model). Milk and plasma samples were analyzed as indicated above. The coefficient of determination $\left(\mathrm{R}^{2}\right)$ for the validation was calculated from the linear regression plotted for these data.

\section{Statistical Analysis}

All statistical analyses were performed in SAS version 9.4 (SAS Institute Inc., Cary, NC). Graphs were created using GraphPad Prism version 8.1 (GraphPad Software, San Diego, CA) and Microsoft Excel (2018; Microsoft Corp., Redmond, WA). Descriptive statistics were performed using PROC FREQ, PROC UNIVARIATE, PROC TTEST, and PROC ANOVA. Correction for multiple comparison was performed using a Bonferroni correction where appropriate.

To examine the effect each EED diagnostic analyte (blood BHB, milk BHB, mpbNEFA, or de novo FA) on changes in SCS, models were built using PROC MIXED, accounting for repeated measurements within cow using the REPEATED statement. Differing SCS dynamics between parity groups (Figure 1) were accounted for by developing repeated-measures models for each parity group $(2: \mathrm{n}=206 ; 3: \mathrm{n}=105$; and $\geq 4$ : $\mathrm{n}=85$ ) for each of the 4 EED diagnostic analytes, for a total of 12 models. Seven covariance structures were tested in all association models (first-order autoregressive, compound symmetry, Toeplitz, the heterogeneous form for the aforementioned, as well as unstructured). The covariance structure yielding the lowest Akaike's information criterion was chosen; in all cases, unstructured fit this criterion.

All models evaluating the effects of EED diagnostic analyte on SCS included the fixed effects of the EED diagnostic analyte (blood BHB, milk BHB, mpbNEFA, or de novo FA rel \%), sampling time point, and other additional explanatory variables as described below. To aid in interpretation, each diagnostic analyte was dichotomized for analysis, and cut points were chosen based on their previously established association with adverse health events: blood $\mathrm{BHB}=1.2 \mathrm{mmol} / \mathrm{L}$, milk $\mathrm{BHB}=0.14 \mathrm{mmol} / \mathrm{L}, \mathrm{mpbNEFA}=0.55 \mathrm{mmol} / \mathrm{L}$, de novo FA $=22.7$ rel \% (Duffield et al., 1998; McArt et al., 2011; Bach et al., 2019). Cows were classified as either above or below the cut point if they crossed that cut point at any time during the first 18 DIM.

Potential risk factors tested for inclusion in the analysis as additional explanatory variables included herd, average weekly milk yield during the sampling period $(\mathrm{kg} / \mathrm{d} ; 3$ to $18 \mathrm{DIM})$, CM diagnosis during the sampling period (3 to 18 DIM), adverse event (DA, metritis, or herd removal) diagnosis during the sampling period (3 to $18 \mathrm{DIM})$, BCS $(<3$ or $\geq 3)$, locomotion score $(\leq 2$ or $>2$ ), and calving ease score, which was dichotomized for animals delivering live singletons with little or no aid during parturition and those with dystocia, twins, or stillbirths. Before being offered to each of the 12 models, correlation between the prospective explanatory variables was examined using PROC CORR, with variables considered associated if their correlation coefficient was $\geq 0.3$; none of the explanatory variables fit this criterion. Because each EED diagnostic analyte was modeled independently, correlation between these variables was not evaluated.

Prospective explanatory variables were explored for their univariable association with the outcome of interest, SCS, using a chi-squared test. Variables with $P$ $<0.20$ were offered to the multivariable model, and backward stepwise elimination using $P>0.10$ was performed for main effects variable selection. Herd was forced into all models to account for potential differences in SCS between the 2 farms. Similarly, average weekly milk yield was forced into all models to account for the effects of milk production on SCS. Potential 2-way interactions between all remaining explanatory variables and the EED diagnostic analyte of interest 
were examined and removed via backward stepwise elimination using $P>0.05$ only if at least $10 \%$ of cows were within each level of the contingency table between both variables in the pairwise interaction.

To explore the association of EED and CM, due to power constraints, all analyses were conducted on the univariate level for each diagnostic analyte, in a continuous form, at each time point, for all parity groups combined using $t$-test analysis. To improve normality of residuals for blood $\mathrm{BHB}$, a $\log _{10}$ transformation was performed. All means for blood BHB presented hereafter represent the back-transformed means and their associated $95 \%$ confidence intervals. Cows were categorized as having a CM event during a particular time point if diagnosis occurred on or after the day of sampling and within the first 60 DIM.

Cows were excluded from analysis if at least one of the following was true: if the previous days carried calf was $<260 \mathrm{~d}(\mathrm{n}=14)$, if they were treated for clinical hypocalcemia $(\mathrm{n}=1)$, if they were prophylactically treated with propylene glycol by on-farm personnel (n $=45$; farm $\mathrm{A}$ only), or if they had a positive culture result at $\leq 3$ DIM (farm A: $\mathrm{n}=15$; farm B: $\mathrm{n}=42$ ). Furthermore, cows that contributed milk samples at $\leq 2$ time points were excluded from analysis $(\mathrm{n}=19)$ unless data were missing due to a herd removal event.

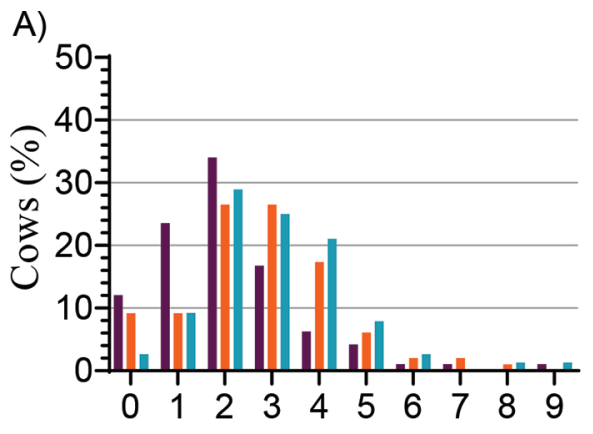

Somatic cell score

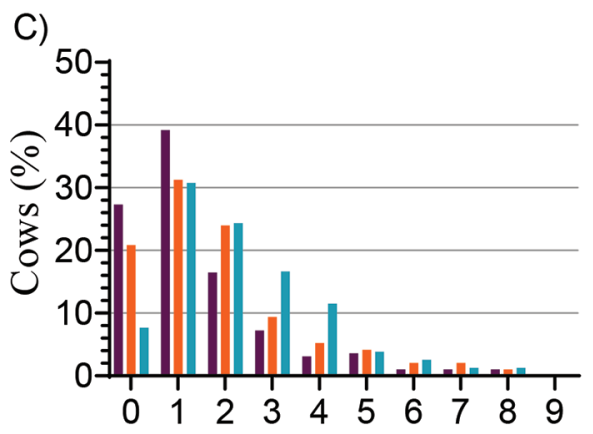

Somatic cell score

\section{RESULTS}

\section{Milk Predicted Blood NEFA Prediction Model and Validation}

The PLS modeling parameters are provided in Table 1. The PLS model for prediction of mpbNEFA included 380 samples and was a 9-factor model with a standard error of cross validation of 172 and a ratio of standard deviation to standard error of cross validation (RPD) of 2.0 .

For the model validation, the mean blood NEFA for the 174 blood samples was $544.4 \mu \mathrm{Eq} / \mathrm{L}$ (min 100 and $\max 1,620)$ and the mean for the mid-infrared mpbNEFA model was $544.0 \mu \mathrm{Eq} / \mathrm{L}(\min 46, \max 1,215)$ with a standard deviation of the difference of $219 \mu \mathrm{Eq} / \mathrm{L}$. A regression graph of the validation data is shown in Figure 2. The $\mathrm{R}^{2}$ for the regression analysis of the validation data was 0.51 .

\section{Descriptive Statistics}

In total, 517 cows were enrolled, with 396 eligible for analysis. The incidence of HYK, as diagnosed by blood BHB between 3 and 18 DIM, was $13.4 \%$. The incidence of adverse event diagnosis (DA, metritis, or

B)

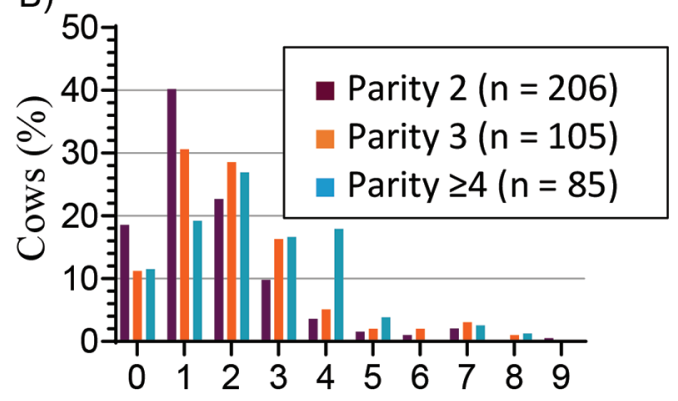

Somatic cell score

D)

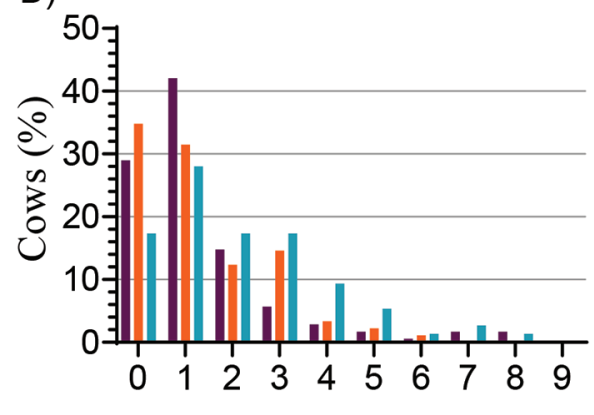

Somatic cell score

Figure 1. Histograms showing data for 396 multiparous Holstein cows from 2 herds undergoing repeated testing for milk SCS by parity group at 4 time points: (A) time point $1=3$ to 7 DIM; (B) time point $2=6$ to 11 DIM; (C) time point $3=10$ to 14 DIM; (D) time point $4=13$ to 18 DIM. SCS $=\log _{2}(\mathrm{SCC} / 100,000)+3$. 
Table 1. Model parameters used to develop a Fourier-transform midinfrared (FTIR), partial least squares (PLS) prediction model for milk predicted blood nonesterified fatty acids (mpbNEFA $)^{1}$

\begin{tabular}{lc}
\hline & FTIR PLS prediction model \\
\cline { 2 - 2 } Item & mpbNEFA \\
\hline Number of samples & 380 \\
Mean & 663.56 \\
SD & 349.3 \\
Minimum & 78.8 \\
Maximum & $1,856.1$ \\
Number of factors & 9 \\
SECV & 172.0 \\
$\mathrm{R}^{2}$ & 0.64 \\
$F$-ratio (PRESS) & 1.01 \\
$F$-test (FPRESS) & 0.56 \\
RPD & 2.0 \\
${ }^{1}$ Number of samples, mean of reference value, SD, minimum and maxi- \\
mum values of final population of samples (i.e., with outliers removed), \\
number of factors, SE of cross validation (SECV), ${ }^{2}, F$-ratio predict- \\
ed residual sum of squares (PRESS), F-test (FPRESS), and the ratio \\
of SD to SE of cross validation (RPD) of the calibration step for the \\
PLS model to predict mpbNEFA expressed as $\mu$ Eq/L. Conversion of \\
mpbNEFA from $\mu$ Eq/L to mmol/L can be performed by the following \\
calculation: $\mu$ Eq/L $\times(0.001$ mEq/1 $\mu$ Eq) $=$ mmol/L.
\end{tabular}

herd removal) during the first 18 DIM was $7.8 \%$, with an individual incidence of DA of $0.3 \%$, metritis of $6.1 \%$, and herd removal of $1.8 \%$. The incidence of $\mathrm{CM}$ in the first 18 DIM was $15.1 \%$ and within the first 60 DIM was $23.9 \%$. Median blood BHB, milk BHB, and mbpNEFA concentrations, and de novo FA rel \% can be found in Table 2. Mean milk fat at each time point was as follows: $\mathrm{T} 1=4.9 \%, \mathrm{~T} 2=4.6 \%, \mathrm{~T} 3=4.3 \%$, and $\mathrm{T} 4$ $=4.1 \%$. Mean true protein was $\mathrm{T} 1=4.0 \%, \mathrm{~T} 2=3.6 \%$, $\mathrm{T} 3=3.3 \%, \mathrm{~T} 4=3.1 \%$. Mean lactose was $\mathrm{T} 1=4.2 \%$, $\mathrm{T} 2=4.4 \%, \mathrm{~T} 3=4.5 \%, \mathrm{~T} 4=4.6 \%$.

Due to CM incidence lower than expected and research protocol drift errors on one of the farms, we calculated a post-hoc power calculation. Power calculations estimate the power of this study at $21 \%$ using a sample size of 396, an incidence of HYK of $13.4 \%$, a

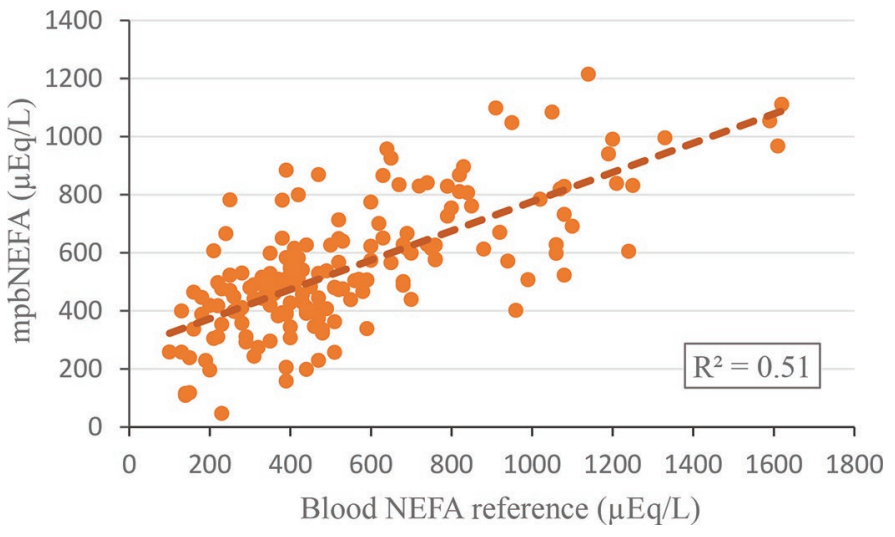

Figure 2. Milk predicted blood nonesterified fatty acids (mpbNEFA) as a function of measured blood NEFA for 174 individual Holstein cow paired blood and milk validation samples. Conversion of mpbNEFA from $\mu \mathrm{Eq} / \mathrm{L}$ to $\mathrm{mmol} / \mathrm{L}$ can be performed by the following calculation: $\mu \mathrm{Eq} / \mathrm{L} \times(0.001 \mathrm{mEq} / 1 \mu \mathrm{Eq})=\mathrm{mmol} / \mathrm{L}$.

type I error level of $5 \%$, a difference in SCS between EED and non-EED animals of 0.2 units and a standard deviation of 1.6 units.

\section{Relationship with SCS}

Descriptive statistics for SCS at each sampling time point are in Table 3. Histograms showing the distribution of SCS for each parity group at each time point are in Figure 1. Mean SCS at each sampling time point for each of the EED diagnostic analytes (blood BHB, milk BHB, mpbNEFA, and de novo FA) for each parity group $(2,3$, and $\geq 4)$ are shown in Figure 3 .

The interaction of diagnostic analyte and time point did not remain in any model (all $P>0.1$ ). Time point had an effect on SCS for all diagnostic analytes in all parity groups, with decreases in SCS observed as time points progressed. This was most pronounced in parity 2 and parity 3 cows (all $P<0.001$ ), and less so

Table 2. Median and range of blood BHB, milk BHB, milk predicted blood nonesterified fatty acids (mpbNEFA), and de novo fatty acids (FA) ${ }^{1}$ for 396 multiparous Holstein cows from 2 herds undergoing repeated sampling for excessive energy deficit via diagnostic blood and milk analytes

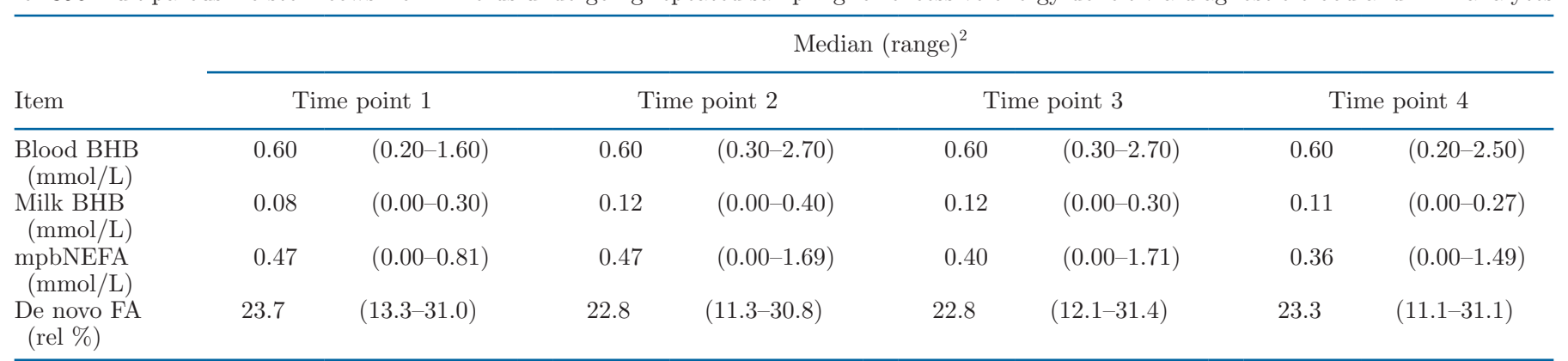

\footnotetext{
${ }^{1}$ Expressed as relative percentage (rel \%).

${ }^{2}$ Sampling time points: $1=3$ to 7 DIM; $2=6$ to 11 DIM; $3=10$ to 14 DIM; $4=13$ to 18 DIM.
} 
for parity $\geq 4$ cows (blood BHB, milk BHB, and de novo FA rel $\%: P=0.07$; mpbNEFA: $P=0.05$ ). Milk predicted blood NEFA was the only diagnostic analyte to show an effect on SCS; this effect was noted only in parity $\geq 4$ cows, with mean SCS for non-EED and EED cows of 3.1 and 2.4 , respectively $(P=0.06)$. However, numerical differences in SCS were observed between non-EED and EED cows in at least one time point for 11 of the 12 models. During T1, SCS was lower for EED cows diagnosed by blood BHB (all parity groups), milk BHB (parity 3 ), mpbNEFA (parity 3 and $\geq 4$ ), and de novo FA rel \% (all parity groups). Moreover, for blood BHB, estimates of mean SCS for non-EED cows were numerically higher than EED cows at T2, T3, and T4 for all parity groups, except for T3 in parity 3 . This trend was also noted for mpbNEFA at all time points in parity $\geq 4$.

Additional variables retained in all 12 diagnostic analyte models were $\mathrm{CM}$ diagnosis during the sampling period (parity 2: all $P<0.001$; parity 3 and $\geq 4$ : all between $P=0.05$ and $P=0.07$ ), farm (parity 2 : all $P$ $\leq 0.004$; parity 3 : all $P \geq 0.6$; parity $\geq 4$ : all $P \geq 0.1$ ), and average daily milk production during the sampling period (parity 2: all $P \geq 0.06$; parity 3 : all $P \geq 0.3$; parity $\geq 4$ : all $P<0.001)$.

\section{Relationship with Clinical Mastitis}

Pathogen results for mastitis detection at freshening and CM cultures are in Table 4. Descriptive statistics for CM diagnosis are in Table 5. Mean concentrations of each diagnostic analyte (blood BHB, milk BHB, mpbNEFA, and de novo FA) by CM diagnosis at each time point are in Figure 4. Relative percentages of de novo FA were lower in cows with subsequent $\mathrm{CM}$ diagnosis at all time points; the greatest difference was observed at T2 $(P=0.03$ following Bonferroni correction). Blood BHB concentrations were also lower for CM cows at T3 ( $P=0.04$ following Bonferroni correction). No other important or consistent trend was observed between any other diagnostic analyte and CM diagnosis.

\section{DISCUSSION}

Consistent with our hypothesis that dysfunction of the immune system as a consequence of EED would result in reduced immune response by the mammary gland, cows considered to have EED, as diagnosed by blood BHB or mpbNEFA concentrations above or de novo FA rel \% below our chosen cut points, tended to have lower SCS than their non-EED counterparts. This was particularly apparent during $\mathrm{T} 1$ and for cows in parity 3 and $\geq 4$ during most other time points (Figure 3 ). Parity $\geq 4$ group, when diagnosed via mpbNEFA, had the greatest differences in mean SCS between EED and non-EED animals, 0.7 SCS units, equating to SCC in EED animals approaching half that of nonEED (mpbNEFA: EED $=67,000$ cells $/ \mathrm{mL}$; non-EED $=107,000$ cell $/ \mathrm{mL}$ ). Because increased parity is associated with risk of HYK (McArt et al., 2013), this may explain the stronger relationship between SCS and EED in these cows.

Table 3. Descriptive statistics for 396 multiparous Holstein cows from 2 herds undergoing repeated testing for milk SCS during sampling time points 1 (3 to 7 DIM), 2 (6 to 11 DIM), 3 (10 to 14 DIM), and 4 (13 to 18 DIM)

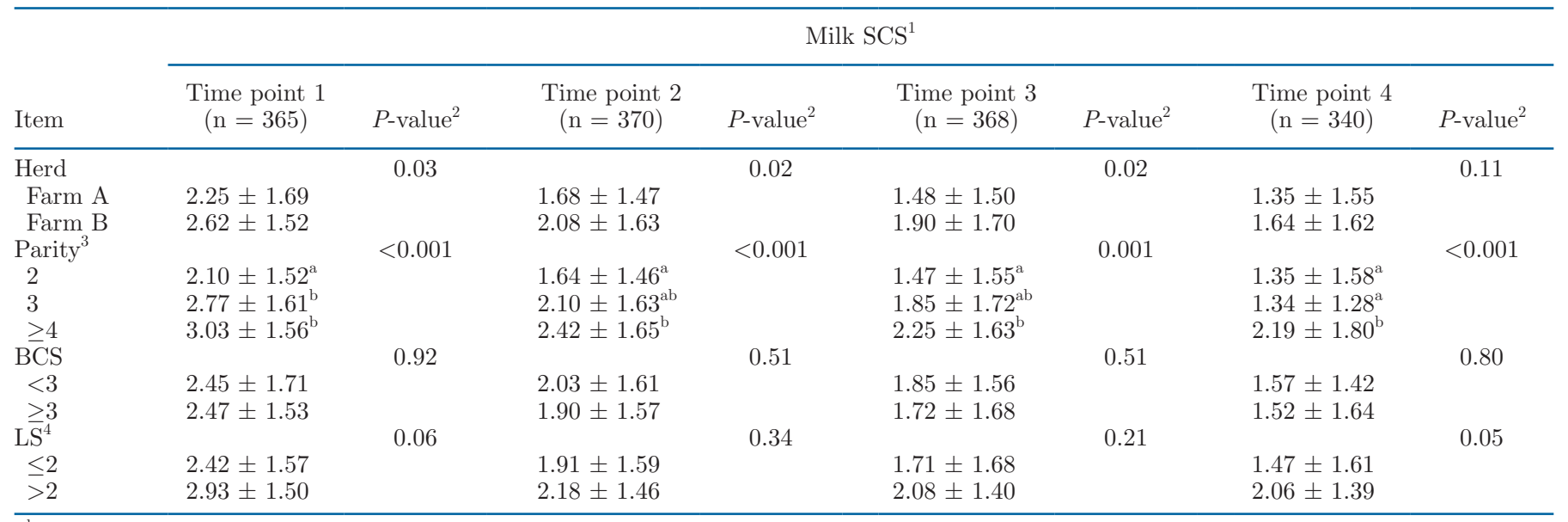

\footnotetext{
${ }^{a, b}$ Different superscripts within a time point indicate differences at $\alpha=0.05$.

${ }^{1}$ Values given as mean $\pm \mathrm{SD}$. SCS $=\log _{2}(\mathrm{SCC} / 100,000)+3$.

${ }^{2} P$-value reported for $t$-statistic (herd, BCS, locomotion score) or $F$-statistic (parity); Bonferroni-adjusted critical threshold: $P<0.01$.

${ }^{3}$ Parity $2: \mathrm{n}=206$; parity $3: \mathrm{n}=105$; parity $\geq 4: \mathrm{n}=85$.

${ }^{4} \mathrm{LS}=$ locomotion score.
} 
In general, a clearer relationship between EED and SCS was observed when diagnosis was performed using blood BHB and mpbNEFA compared with milk BHB or de novo FA rel \% during the sampling window that we chose (3 to 18 DIM). This is indicated by more consistent trends observed in the SCS models (Figure 3). A previous report by our group (Bach et al., 2019) demonstrated a poor diagnostic ability for milk BHB during early lactation (3 to 18 DIM). We hypothesized that this was most likely due to a delay in the increase in milk BHB compared with blood BHB (de Roos et al., 2007; Santschi et al., 2016). Because our sampling window was chosen based on optimal sampling times for HYK diagnosis using blood BHB (3 to 14 DIM;
A) Parity $2(\mathrm{n}=206)$

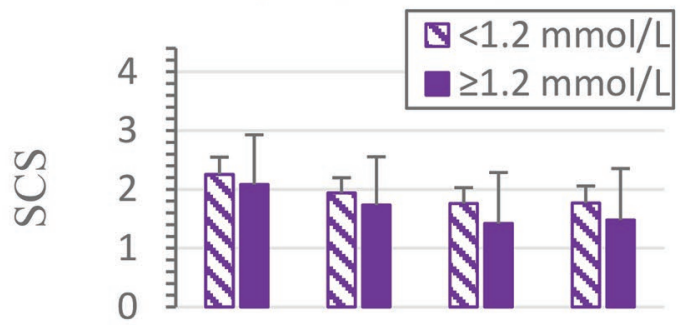

B)

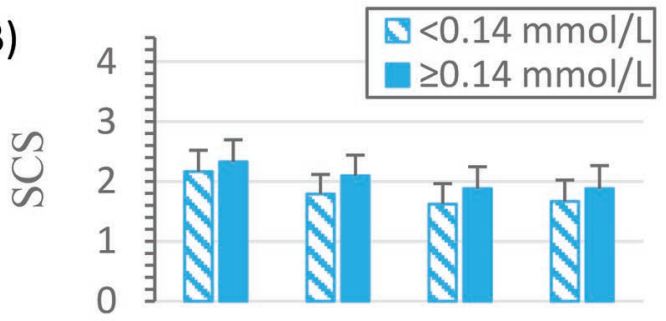

C)

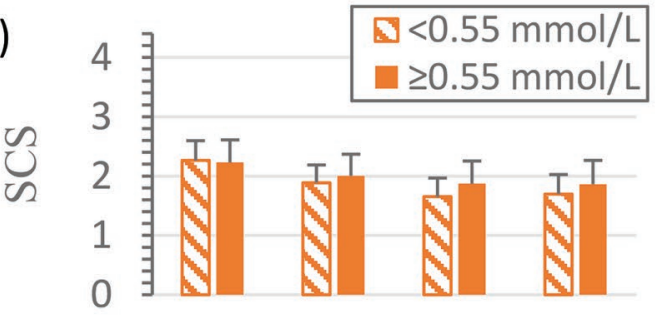

D)

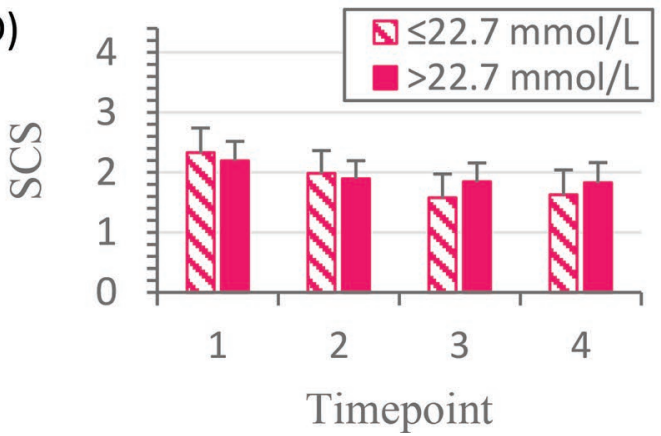

Parity $3(n=105)$
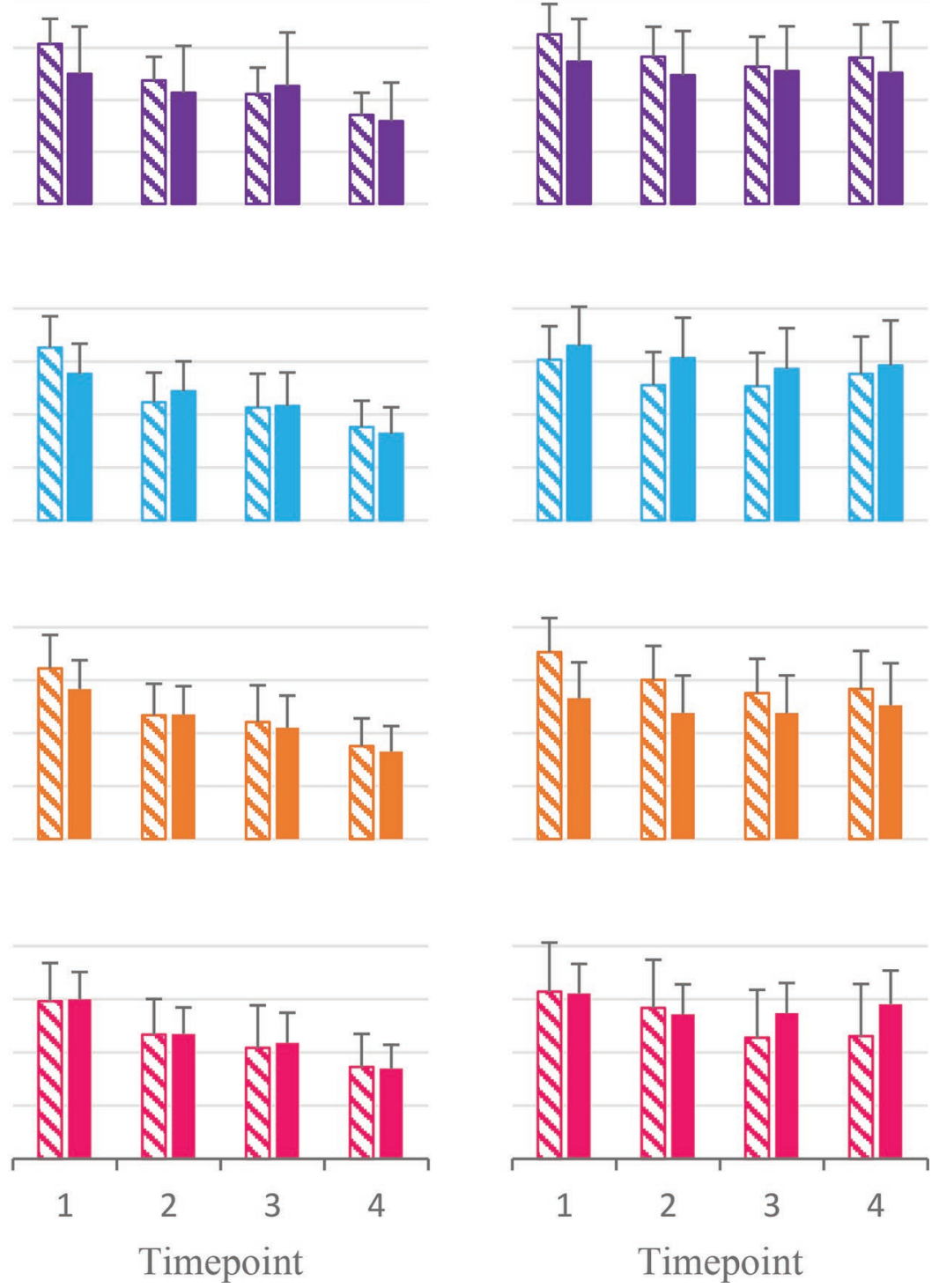

Parity $\geq 4(\mathrm{n}=85)$

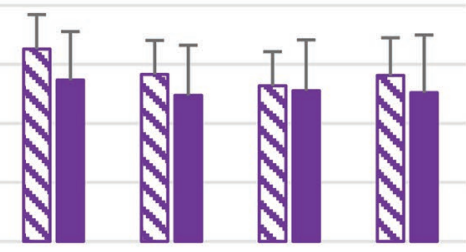

Figure 3. Mean milk SCS during the first 18 DIM for excessive energy deficit diagnostic analytes: (A) blood BHB, (B) milk BHB, (C) milk predicted blood nonesterified fatty acids (mpbNEFA), and (D) de novo fatty acids (FA; relative percentage, rel \%) by parity group for 396 Holstein cows from 2 herds. Cows above the cut point for (A) blood BHB (purple bars), (B) milk BHB (blue bars), (C) mpbNEFA (orange bars), or below the cut point for (D) de novo FA rel \% (pink bars) are denoted by solid bars, and their counterparts are denoted by striped bars of the corresponding color. The interaction of diagnostic analyte and time point did not remain in final models for any parity group (all $P>$ 0.1). Error bars represent 95\% CI. 
Table 4. Aerobic culture results for fresh cultures from 438 multiparous Holstein cows sampled 1 to 3 DIM, and clinical mastitis cultures from 396 multiparous Holstein cows sampled from 4 to 60 DIM

\begin{tabular}{|c|c|c|c|c|}
\hline \multirow{3}{*}{$\begin{array}{l}\text { Pathogen isolated } \\
\text { Negative }\end{array}$} & \multicolumn{2}{|c|}{$\begin{array}{l}\text { Fresh cultures }^{1} \\
\quad(\mathrm{n}=438)\end{array}$} & \multicolumn{2}{|c|}{$\begin{array}{c}\text { Clinical mastitis cultures }{ }^{1} \\
(\mathrm{n}=94)\end{array}$} \\
\hline & \multicolumn{2}{|c|}{ No. (\% total fresh cultures) } & \multicolumn{2}{|c|}{ No. (\% total clinical cultures) } \\
\hline & 242 & $(55.3)$ & 24 & $(25.5)$ \\
\hline No culture data ${ }^{2}$ & 154 & $(35.2)$ & - & - \\
\hline Corynebacterium spp. & 0 & $(0.0)$ & 8 & $(8.5)$ \\
\hline Enterococcus spp. & 2 & $(0.5)$ & 0 & $(0.0)$ \\
\hline Escherichia coli & 1 & $(0.2)$ & 18 & (19.1) \\
\hline Gram-positive Bacillus spp. & 2 & $(0.5)$ & 1 & $(1.1)$ \\
\hline Klebsiella spp. & 2 & $(0.5)$ & 6 & $(6.4)$ \\
\hline Staphylococcus aureus & 5 & $(1.1)$ & 6 & $(6.4)$ \\
\hline Staphylococcus spp. & 20 & $(4.6)$ & 18 & $(19.1)$ \\
\hline Streptococcus dysgalactiae & 1 & $(0.2)$ & 3 & $(3.2)$ \\
\hline Streptococcus uberis & 1 & $(0.2)$ & 2 & $(2.1)$ \\
\hline Streptococcus spp. & 3 & $(0.7)$ & 3 & $(3.2)$ \\
\hline Trueperella pyogenes & 0 & $(0.0)$ & 3 & $(3.2)$ \\
\hline Yeast or other & 5 & $(1.1)$ & 2 & $(2.1)$ \\
\hline
\end{tabular}

Ospina et al., 2010), further studies lengthening the sampling window are necessary to further explain this relationship.

Previous reports regarding SCC in EED cows are mixed. Research from Santschi et al. (2016) utilizing FTIR-predicted milk BHB demonstrated that cows with elevations in milk BHB $>0.15 \mathrm{mmol} / \mathrm{L}$ had higher SCC and SCS. However, the aforementioned study utilized test day data with cows ranging from 5 to 35 DIM, with an average DIM at first test between 18 to $20 \mathrm{~d}$. Because periparturient reductions in immune cell populations appear to resolve within 2 wk postpartum

Table 5. Descriptive statistics and chi-squared analyses for 396 multiparous Holstein cows from 2 herds diagnosed with clinical mastitis between 4 and 60 DIM

\begin{tabular}{|c|c|c|c|c|c|}
\hline \multirow[b]{2}{*}{ Item } & \multicolumn{5}{|c|}{$\begin{array}{c}\text { Clinical mastitis diagnosis } \\
\text { no. }(\%)\end{array}$} \\
\hline & & No & & Yes & $P$-value ${ }^{1}$ \\
\hline Herd $(\mathrm{n}=396)$ & & & & & $<0.001$ \\
\hline Farm A & 92 & $(23.2)$ & 63 & $(15.9)$ & \\
\hline Farm B & 209 & $(52.8)$ & 32 & $(8.1)$ & \\
\hline Parity $(\mathrm{n}=396)$ & & & & & 0.70 \\
\hline 2 & 153 & $(38.6)$ & 53 & $(13.4)$ & \\
\hline 3 & 82 & $(20.7)$ & 23 & $(5.8)$ & \\
\hline$\geq 4$ & 66 & $(16.7)$ & 19 & $(4.8)$ & \\
\hline$\overline{\mathrm{BCS}}(\mathrm{n}=387)$ & & & & & 0.38 \\
\hline$<3$ & 67 & $(17.3)$ & 25 & $(6.5)$ & \\
\hline$\geq 3$ & 228 & $(58.9)$ & 67 & $(17.3)$ & \\
\hline$\overline{L S}^{2}(\mathrm{n}=384)$ & & & & & 0.56 \\
\hline$\leq 2$ & 261 & $(68.0)$ & 83 & $(21.6)$ & \\
\hline$>2$ & 32 & $(8.3)$ & 8 & $(2.1)$ & \\
\hline
\end{tabular}

${ }^{1} P$-value reported for $\chi^{2}$ statistic.

${ }^{2} \mathrm{LS}=$ locomotion score.
(Kimura et al.,1999), the majority of cows from Santschi et al. (2016) would have resolved these reductions, which may explain the higher SCC and SCS found in that study. The majority of SCS differences between EED and non-EED cows in the current study were observed during T1 (3 to 7 DIM). Furthermore, cows diagnosed with EED during the third week of lactation or later may not be at risk for the same downstream negative effects of EED as those cows diagnosed within the first or second weeks. When examining EED in relation to milk production, research suggests that timing of diagnosis may be important when identifying these types of associations (Duffield et al., 2009; McArt et al., 2012).

Conversely, work by Rathbun et al. (2017) found results similar to those of our study by demonstrating a reduction in log-transformed SCC during the first 3 wk of lactation for HYK cows, compared with their non-HYK counterparts. Milk production in that study was similar to the current study. Likewise, Nyman et al. (2008) showed that heifers with increased blood BHB concentration before calving had decreased Box-Cox transformed SCC after calving. And although a large field study in the Netherlands found no relationship between HYK and SCC, numerically cows with HYK had a lower SCC at first DHIA test (Vanholder et al., 2015).

This lack of consensus regarding the relationship between EED and SCC is only highlighted by a recent meta-analysis looking at diseases associated with HYK. Although the analysis determined that animals with HYK were more likely to have a doubling of SCC, the authors made sure to point out that studies reporting 
A)

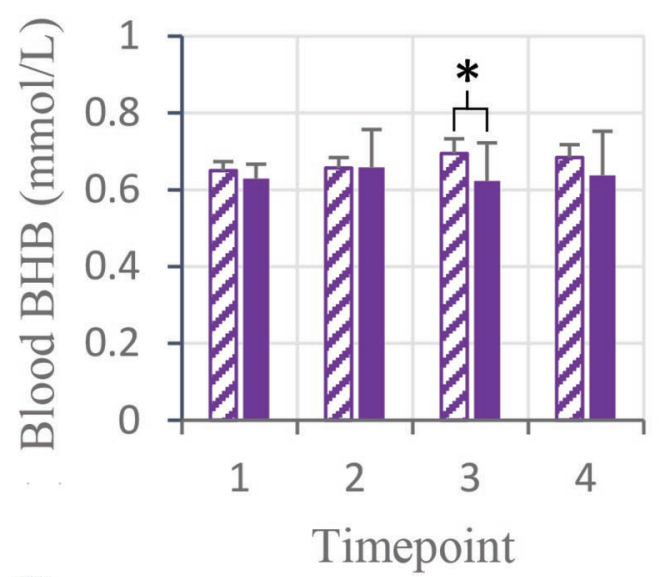

C)

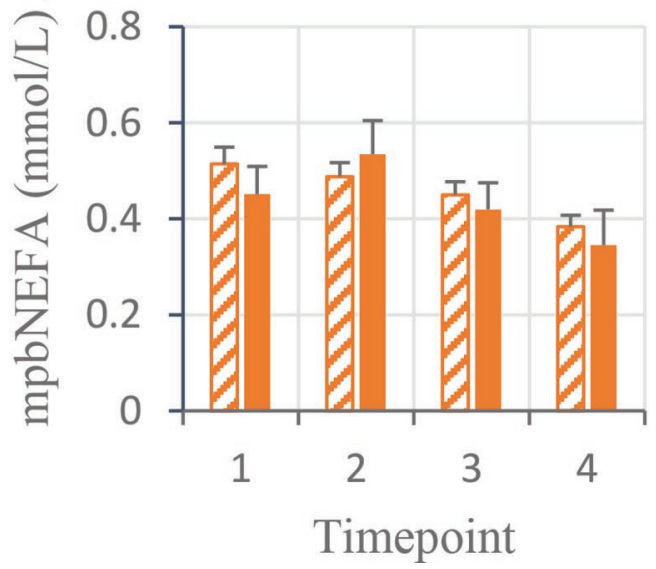

B)

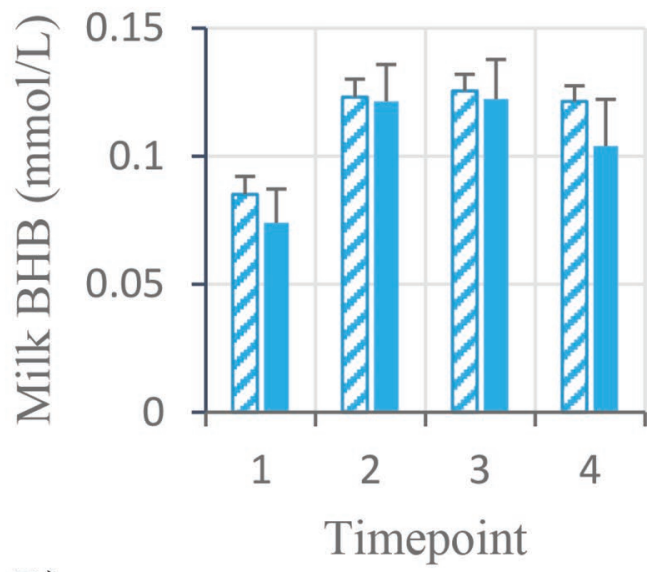

D)

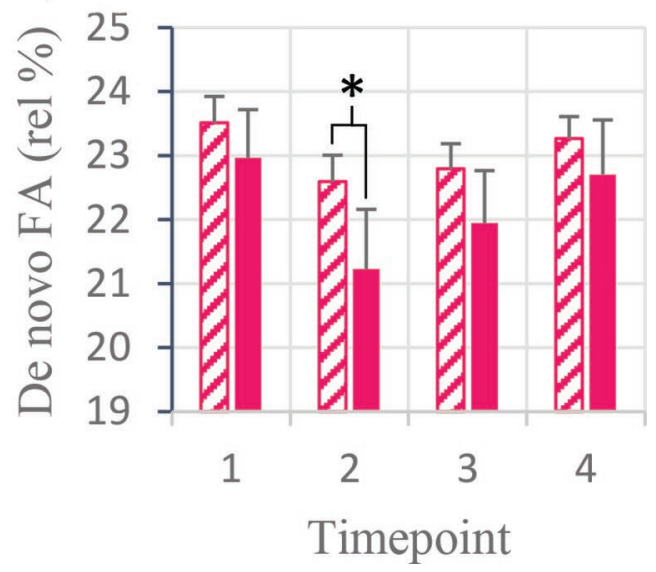

Figure 4. $t$-Test analysis for mean concentration of excessive energy deficit diagnostic analytes: (A) blood BHB, (B) milk BHB, (C) milk predicted blood nonesterified fatty acids (mpbNEFA), and (D) de novo fatty acids (FA; relative percentage, rel \%) for 396 Holstein cows from

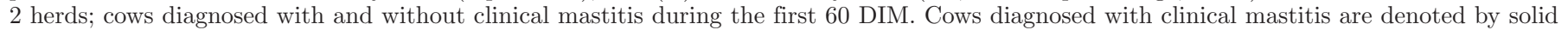

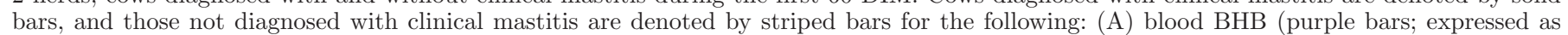

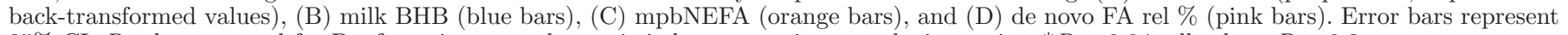
$95 \%$ CI. $P$-value reported for Bonferroni-corrected $t$-statistic between pairs at each time point: $* P<0.04 ;$ all others $P>0.3$.

SCC are scarce (Raboisson et al., 2014). Furthermore, the relationship between EED and SCC was not an objective of either of the studies examined in the metaanalysis (Leslie et al., 2000; van Straten et al., 2009). The lack of consensus may also suggest that HYK is not the best measure of the association between mammary health and EED, because EED is multifactorial disease process with effects on both nutrient availability and immune function (Sordillo, 2016).

Although few conclusions can be drawn regarding the association of EED and CM diagnosis in our study, given the low power, our results provide some evidence that concentrations of EED diagnostic analytes may differ between animals diagnosed with $\mathrm{CM}$ and those not so diagnosed. As can be seen in Figure 4, no meaningful or consistent trends can be seen for blood BHB, milk BHB, or mpbNEFA between cows diagnosed with $\mathrm{CM}$ and those not. However, milk de novo FA rel \% was consistently lower in cows with subsequent CM diagnosis. Previous work from our group has demonstrated that cows diagnosed with other adverse events (HYK, DA, metritis, died or sold) had lower de novo FA rel \% before diagnosis. Furthermore, these differences were small; even decreases as small as $2 \%$ were associated with increased risk of adverse event occurrence (Bach et al., 2019). Additional studies with greater power may be able to clarify the relationship between de novo FA rel \% and CM diagnosis.

One potential explanation for the lack of similar trends in blood BHB, milk BHB, or mpbNEFA could be compliance issues during sample collection for mastitis detection at freshening for farm A. For this herd, 
we had few samples collected during 1 to 3 DIM for mastitis detection at freshening and, instead, a large proportion of composite milk samples collected between 4 and 9 DIM. Because we have no way of knowing whether these samples were intended as samples for mastitis detection at freshening or as CM samples, we made the decision to record culture-negative results from these 4 to 9 DIM composite milk samples as those collected for mastitis detection at freshening. Culturepositive results from the aforementioned samples were assumed to not have mastitis upon entering lactation and were treated as samples collected for CM detection, the latter accounting for almost $50 \%$ of all CM cultures collected. Due to these assumptions, early-lactation culture-negative CM cases may have been falsely reduced. Additionally, some cows that would otherwise have been excluded from our analysis due to positive cultures at freshening might not have been excluded. Both cases result in bias.

Furthermore, misclassification of culture samples could affect the concentration of EED diagnostic analytes. During analysis, cows were categorized as having a CM event during a particular time point only if diagnosis occurred on or after the day of sampling, to ensure that EED classification occurred before CM identification. Because studies have shown that blood BHB decreases following intramammary challenge with Escherichia coli and intravenous LPS infusion (Waldron et al., 2003; Moyes et al., 2014), the lower concentration of blood and milk BHB may be a result of infection occurring before EED diagnosis. However, for blood FA, reports have shown increases in this analyte following LPS infusion and no change following intramammary challenge with Streptococcus uberis (Moyes et al., 2009a, 2014).

Similar to SCC, little consensus exists in the literature regarding the relationship between EED and CM. A few studies examining this relationship have noted elevations in blood BHB and blood FA in cows with CM (Moyes et al., 2009b; Raboisson et al., 2014); however, at least one study in grazing heifers by Compton et al. (2007) demonstrated an association between reductions in post-calving blood FA concentrations and increased incidence of CM.

Regardless, SCC and SCS are expected to be elevated during the first 2 to $4 \mathrm{wk}$ of lactation in cows both with and without intramammary infections (Dohoo and Meek, 1982; Dohoo, 1993). Reductions in SCC are thought to predispose cows to a higher risk of CM due to the reduced presence of leukocytes required to resolve the infection (Suriyasathaporn et al., 2000). This appears to be true both at the individual cow level (SCC $<36,000$; Schukken et al., 1999) and on the herd level in herds with 40 to $60 \%$ of their cows with SCC $<50,000$ cells/mL or bulk tank SCC $<150,000$ (Suriyasathaporn et al., 2000; Beaudeau et al., 2002). In our study, mean SCS for EED and non-EED cows, classified by blood BHB, were 2.1 (SCC: 54,300 cells $/ \mathrm{mL}$ ) and 2.4 units (SCC: $65,200 \mathrm{cell} / \mathrm{mL}$ ), respectively, and by mpbNEFA were 2.2 (SCC: 58,000 cells $/ \mathrm{mL}$ ) and 2.4 units (SCC: 68,300 cell $/ \mathrm{mL}$ ), respectively, suggesting that SCS in EED cows may have been low enough to predispose them to CM. Unfortunately, power limitations most likely affected our ability to appropriately answer this question.

A lack of power was the main limitation of our study. Incidence of EED was lower than expected, with an incidence of HYK (a proxy for EED) of only 13.4\%. Reported incidence of HYK in North America range from 40 to 60\% (Duffield et al., 1998; McArt et al., 2012). Additionally, exclusions required due to prophylactic propylene glycol treatment and compliance issues on farm all resulted in a much smaller sample size than anticipated and, subsequently, a power of less than $30 \%$. This low power most likely limited our ability to fully elucidate the dynamics of SCS and the association between EED and CM incidence.

Our study illustrates the validation of the current PLS model for predicted blood NEFA from milk (i.e., mpbNEFA), although these models have been previously described (Barbano et al., 2015; Woolpert et al., 2016). As can be seen from the RPD value of 2 , this model demonstrates that mid-infrared data are useful as a screening method for EED. The higher the RPD value, the greater the standard deviation of an accurate prediction of an unknown sample. If the standard error of cross validation is large compared with the standard deviation, resulting in a small RPD, the PLS model is considered less robust. An RPD value between 2 and 5 indicates that the calibration may be useful for screening purposes (i.e., qualitative determination; Williams, 2010). The $R^{2}$ for the validation regression data set is consistent with the RPD for the PLS model.

\section{CONCLUSIONS}

Our study demonstrated that cows diagnosed with EED using blood BHB, milk BHB, or mpbNEFA concentrations, or milk de novo FA rel \% during the first 18 DIM have a tendency toward lower SCS compared with their non-EED counterparts. The relationship between EED and CM remains unclear. Despite the power of this study limiting our ability to fully explicate these associations, our findings provide evidence to support further exploration of the relationship between EED and SCS. 


\section{ACKNOWLEDGMENTS}

This study was funded by the USDA National Institute of Food and Agriculture (Washington, DC) Hatch project no. 1007331. The authors thank Nova Biomedical (Waltham, MA) for providing BHB meters and strips, Charlene Ryan, Rafael Neves, Stephanie Tarlowe, Jamie Horstmann, and Mariah Goodwin (Cornell University, Ithaca, NY) for their assistance with sample collection, and Chassidy Coon and the rest of the Barbano Laboratory (Cornell University) for milk analysis. We also thank the owners of the collaborating dairies for allowing us access to their cows and facilities on which to conduct this research. The authors state that there are no conflicts of interest.

\section{REFERENCES}

Ali, A. K. A., and G. E. Shook. 1980. An optimum transformation for somatic cell concentration in milk. J. Dairy Sci. 63:487-490. https: //doi.org/10.3168/jds.S0022-0302(80)82959-6.

Bach, K. D., D. M. Barbano, and J. A. A. McArt. 2019. Association of mid-infrared-predicted milk and blood constituents with earlylactation disease, removal, and production outcomes in Holstein cows. J. Dairy Sci. 102:10129-10139. https://doi.org/10.3168/jds 2019-16926.

Baird, G. D. 1982. Primary ketosis in the high-producing dairy cow: Clinical and subclinical disorders, treatment, prevention, and outlook. J. Dairy Sci. 65:1-10. https://doi.org/10.3168/jds.S0022 $-0302(82) 82146-2$.

Barbano, D.M., P. Cree, T.R. Overton, H.M. Dann, and R.J. Grant. 2015. Prediction of blood nonesterified fatty acid (NEFA) by FTIR analysis of individual cow milk samples. J. Dairy Sci. 98(Suppl. 2):553.

Bauman, D. E., and W. B. Currie. 1980. Partitioning of nutrients during pregnancy and lactation: A review of mechanisms involving homeostasis and homeorhesis. J. Dairy Sci. 63:1514-1529. https:// doi.org/10.3168/jds.S0022-0302(80)83111-0.

Beaudeau, F., C. Fourichon, H. Seegers, and N. Bareille. 2002. Risk of clinical mastitis in dairy herds with a high proportion of low individual milk somatic-cell counts. Prev. Vet. Med. 53:43-54. https:/ /doi.org/10.1016/S0167-5877(01)00275-6.

Chapinal, N., M. Carson, T. F. Duffield, M. Capel, S. Godden, M. Overton, J. E. P. Santos, and S. J. LeBlanc. 2011. The association of serum metabolites with clinical disease during the transition period. J. Dairy Sci. 94:4897-4903. https://doi.org/10.3168/jds $.2010-4075$.

Compton, C. W. R., C. Heuer, K. Parker, and S. McDougall. 2007. Risk factors for peripartum mastitis in pasture-grazed dairy heifers. J. Dairy Sci. 90:4171-4180. https://doi.org/10.3168/jds.2006 -882 .

de Roos, A. P. W., H. J. C. M. van den Bijgaart, J. Hørlyk, and G. de Jong. 2007. Screening for subclinical ketosis in dairy cattle by Fourier transform infrared spectrometry. J. Dairy Sci. 90:1761-1766. https://doi.org/10.3168/jds.2006-203.

Dohoo, I. R. 1993. An evaluation of the validity of individual cow somatic cell counts from cows in early lactation. Prev. Vet. Med. 16:103-110. https://doi.org/10.1016/0167-5877(93)90080-D.

Dohoo, I. R., and A. H. Meek. 1982. Somatic cell counts in bovine milk. Can. Vet. J. 23:119-125.

Duffield, T. F., K. D. Lissemore, B. W. McBride, and K. E. Leslie. 2009. Impact of hyperketonemia in early lactation dairy cows on health and production. J. Dairy Sci. 92:571-580. https://doi.org/ 10.3168/jds.2008-1507.

Duffield, T. F., D. Sandals, K. E. Leslie, K. Lissemore, B. W. McBride, J. H. Lumsden, P. Dick, and R. Bagg. 1998. Efficacy of monensin for the prevention of subclinical ketosis in lactating dairy cows. J. Dairy Sci. 81:2866-2873. https://doi.org/10.3168/jds.S0022 -0302(98)75846-1.

Erb, H. N., and Y. T. Grohn. 1988. Epidemiology of metabolic disorders in the periparturient dairy cow. J. Dairy Sci. 71:2557-2571. https://doi.org/10.3168/jds.S0022-0302(88)79845-8.

Ferguson, J. D., D. T. Galligan, and N. Thomsen. 1994. Principal descriptors of body condition score in Holstein cows. J. Dairy Sci. 77:2695-2703. https://doi.org/10.3168/jds.S0022-0302(94)77212 $-\mathrm{X}$.

Fitts, J. E., and D. Laird. 2004. Direct microscopic method for bacteria or somatic cells. Standard Methods for the Examination of Dairy Products (17th ed.). H. M. Wehr and J. F. Frank, ed. American Public Health Association, Washington, DC.

Hammon, D. S., I. M. Evjen, T. R. Dhiman, J. P. Goff, and J. L. Walters. 2006. Neutrophil function and energy status in Holstein cows with uterine health disorders. Vet. Immunol. Immunopathol. 113:21-29. https://doi.org/10.1016/j.vetimm.2006.03.022.

Herdt, T. H. 2000. Ruminant adaptation to negative energy balance. Influences on the etiology of ketosis and fatty liver. Vet. Clin. North Am. Food Anim. Pract. 16:215-230. https://doi.org/10 .1016/S0749-0720(15)30102-X.

Hoeben, D., R. Heyneman, and C. Burvenich. 1997. Elevated levels of $\beta$-hydroxybutyric acid in periparturient cows and in vitro effect on respiratory burst activity of bovine neutrophils. Vet. Immunol. Immunopathol. 58:165-170. https://doi.org/10.1016/S0165 -2427(97)00031-7.

Iwersen, M., D. Klein-Jöbstl, M. Pichler, L. Roland, B. Fidlschuster, I. Schwendenwein, and M. Drillich. 2013. Comparison of 2 electronic cowside tests to detect subclinical ketosis in dairy cows and the influence of the temperature and type of blood sample on the test results. J. Dairy Sci. 96:7719-7730. https://doi.org/10.3168/ jds.2013-7121.

Kehrli, M. E. Jr., B. J. Nonnecke, and J. A. Roth. 1989. Alterations in bovine lymphocyte function during the periparturient period. Am J. Vet. Res. 50:215-220.

Kimura, K., J. P. Goff, M. E. Kehrli Jr., and J. A. Harp. 1999. Phenotype analysis of peripheral blood mononuclear cells in periparturient dairy cows. J. Dairy Sci. 82:315-319. https://doi.org/10.3168/ jds.S0022-0302(99)75238-0.

Kluciński, W., A. Degórski, E. Miernik-Degórska, S. Targowski, A. Winnicka, W. Klucinski, A. Degorski, E. Miernik-Degorska, S. Targowski, and A. Winnicka. 1988. Effect of ketone bodies on the phagocytic activity of bovine milk macrophages and polymorphonuclear leukocytes. Zentralbl Veterinarmed A 35:632-639.

Leslie, K.E., T.F. Duffield, Y.H. Schukken, and S.J. Leblanc. 2000. The influence of negative energy balance on udder health. Proc. Natl. Mastitis Council Regional Meeting, Madison, WI.

Luke, T. D. W., S. Rochfort, W. J. Wales, V. Bonfatti, L. Marett, and J. E. Pryce. 2019. Metabolic profiling of early-lactation dairy cows using milk mid-infrared spectra. J. Dairy Sci. 102:1747-1760 https://doi.org/10.3168/jds.2018-15103.

McArt, J. A. A., D. V. Nydam, and G. R. Oetzel. 2012. Epidemiology of subclinical ketosis in early lactation dairy cattle. J. Dairy Sci. 95:5056-5066. https://doi.org/10.3168/jds.2012-5443.

McArt, J. A. A., D. V. Nydam, and G. R. Oetzel. 2013. Dry period and parturient predictors of early lactation hyperketonemia in dairy cattle. J. Dairy Sci. 96:198-209. https://doi.org/10.3168/ jds.2012-5681.

McArt, J. A. A., D. V. Nydam, P. A. Ospina, and G. R. Oetzel. 2011. A field trial on the effect of propylene glycol on milk yield and resolution of ketosis in fresh cows diagnosed with subclinical ketosis. J. Dairy Sci. 94:6011-6020. https://doi.org/10.3168/jds.2011 $-4463$.

Megahed, A. A., M. W. H. Hiew, J. R. Townsend, and P. D. Constable. 2017. Characterization of the analytic performance of an electrochemical point-of-care meter for measuring $\beta$-hydroxybutyrate concentration in blood and plasma from periparturient dairy cattle. Vet. Clin. Pathol. 46:314-325. https://doi.org/10.1111/vcp.12493.

Moyes, K. M., J. K. Drackley, J. L. Salak-Johnson, D. E. Morin, J. C. Hope, and J. J. Loor. 2009a. Dietary-induced negative energy bal- 
ance has minimal effects on innate immunity during a Streptococcus uberis mastitis challenge in dairy cows during midlactation. J. Dairy Sci. 92:4301-4316. https://doi.org/10.3168/jds.2009-2170.

Moyes, K. M., T. Larsen, N. C. Friggens, J. K. Drackley, and K. L. Ingvartsen. 2009b. Identification of potential markers in blood for the development of subclinical and clinical mastitis in dairy cattle at parturition and during early lactation. J. Dairy Sci. 92:54195428. https://doi.org/10.3168/jds.2009-2088.

Moyes, K. M., T. Larsen, P. Sørensen, and K. L. Ingvartsen. 2014. Changes in various metabolic parameters in blood and milk during experimental Escherichia coli mastitis for primiparous Holstein dairy cows during early lactation. J. Anim. Sci. Biotechnol. 5:47. https://doi.org/10.1186/2049-1891-5-47.

Nyman, A.-K., U. Emanuelson, K. Holtenius, K. L. Ingvartsen, T. Larsen, and K. Persson Waller. 2008. Metabolites and immune variables associated with somatic cell counts of primiparous dairy cows. J. Dairy Sci. 91:2996-3009. https://doi.org/10.3168/jds.2007 $-0969$.

Oltenacu, P. A. A., and I. Ekesbo. 1994. Epidemiological study of clinical mastitis in dairy cattle. Vet. Res. 25:208-212.

Ospina, P. A. A., D. V. V. Nydam, T. Stokol, and T. R. R. Overton. 2010. Evaluation of nonesterified fatty acids and $\beta$-hydroxybutyrate in transition dairy cattle in the northeastern United States: Critical thresholds for prediction of clinical diseases. J. Dairy Sci. 93:546-554. https://doi.org/10.3168/jds.2009-2277.

Palmquist, D. L., C. L. Davis, R. E. Brown, and D. S. Sachan. 1969. Availability and metabolism of various substrates in ruminants. V. Entry rate into the body and incorporation into milk fat of $\mathrm{D}(-)$ ß-hydroxybutyrate. J. Dairy Sci. 52:633-638. https://doi.org/10 .3168/jds.S0022-0302(69)86620-8.

Raboisson, D., M. Mounié, and E. Maigné. 2014. Diseases, reproductive performance, and changes in milk production associated with subclinical ketosis in dairy cows: A meta-analysis and review. J. Dairy Sci. 97:7547-7563. https://doi.org/10.3168/jds.2014-8237.

Rathbun, F. M., R. S. Pralle, S. J. Bertics, L. E. Armentano, K. Cho, C. Do, K. A. Weigel, and H. M. White. 2017. Relationships between body condition score change, prior mid-lactation phenotypic residual feed intake, and hyperketonemia onset in transition dairy cows. J. Dairy Sci. 100:3685-3696. https://doi.org/10.3168/ jds.2016-12085.

Santschi, D. E., R. Lacroix, J. Durocher, M. Duplessis, R. K. Moore, and D. M. Lefebvre. 2016. Prevalence of elevated milk $\beta$-hydroxybutyrate concentrations in Holstein cows measured by Fourier-transform infrared analysis in Dairy Herd Improvement milk samples and association with milk yield and components. J. Dairy Sci. 99:9263-9270. https://doi.org/10.3168/jds.2016-11128.

Schukken, Y. H., K. E. Leslie, D. A. Barnum, B. A. Mallard, J. H. Lumsden, P. C. Dick, G. H. Vessie, and M. E. Kehrli. 1999. Experimental Staphylococcus aureus intramammary challenge in late lactation dairy cows: Quarter and cow effects determining the probability of infection. J. Dairy Sci. 82:2393-2401. https://doi .org/10.3168/jds.S0022-0302(99)75490-1.

Sordillo, L. M. 2016. Nutritional strategies to optimize dairy cattle immunity. J. Dairy Sci. 99:4967-4982. https://doi.org/10.3168/jds .2015-10354.
Sprecher, D. J. J., D. E. E. Hostetler, and J. B. B. Kaneene. 1997 A lameness scoring system that uses posture and gait to predict dairy cattle reproductive performance. Theriogenology 47:11791187. https://doi.org/10.1016/S0093-691X(97)00098-8.

Suriyasathaporn, W., A. J. J. M. Daemen, E. N. NoordhuizenStassen, S. J. Dieleman, M. Nielen, and Y. H. Schukken. 1999 $\beta$-Hydroxybutyrate levels in peripheral blood and ketone bodies supplemented in culture media affect the in vitro chemotaxis of bovine leukocytes. Vet. Immunol. Immunopathol. 68:177-186. https: //doi.org/10.1016/S0165-2427(99)00017-3.

Suriyasathaporn, W., Y. H. Schukken, M. Nielen, and A. Brand. 2000. Low somatic cell count: A risk factor for subsequent clinical mastitis in a dairy herd. J. Dairy Sci. 83:1248-1255. https://doi.org/10 .3168/jds.S0022-0302(00)74991-5.

van Hoeij, R. J., T. J. G. M. Lam, R. M. Bruckmaier, J. Dijkstra, G. J. Remmelink, B. Kemp, and A. T. M. van Knegsel. 2018. Udder health of dairy cows fed different dietary energy levels after a short or no dry period without use of dry cow antibiotics. J. Dairy Sci. 101:4570-4585. https://doi.org/10.3168/jds.2017-13448.

van Straten, M., M. Friger, and N. Y. Shpigel. 2009. Events of elevated somatic cell counts in high-producing dairy cows are associated with daily body weight loss in early lactation. J. Dairy Sci 92:4386-4394. https://doi.org/10.3168/jds.2009-2204.

Vanholder, T., J. Papen, R. Bemers, G. Vertenten, and A. C. B. Berge 2015. Risk factors for subclinical and clinical ketosis and association with production parameters in dairy cows in the Netherlands. J. Dairy Sci. 98:880-888. https://doi.org/10.3168/jds.2014-8362.

Waldron, M. R., T. Nishida, B. J. Nonnecke, and T. R. Overton. 2003. Effect of lipopolysaccharide on indices of peripheral and hepatic metabolism in lactating cows. J. Dairy Sci. 86:3447-3459. https:// doi.org/10.3168/jds.S0022-0302(03)73949-6.

Williams, P. 2010. The Analysis of Wheat by Near-Infrared Spectroscopy. E. C. Y. Li-Chan, ed. John Wiley and Sons Ltd., Chichester, UK.

Wojciechowski, K. L., and D. M. Barbano. 2016. Prediction of fatty acid chain length and unsaturation of milk fat by mid-infrared milk analysis. J. Dairy Sci. 99:8561-8570. https://doi.org/10 .3168/jds.2016-11248.

Woolpert, M. E., H. M. Dann, K. W. Cotanch, C. Melilli, L. E. Chase, R. J. Grant, and D. M. Barbano. 2016. Management, nutrition, and lactation performance are related to bulk tank milk de novo fatty acid concentration on northeastern US dairy farms. J. Dairy Sci. 99:8486-8497. https://doi.org/10.3168/jds.2016-10998.

\section{ORCIDS}

K. D. Bach ๑ https://orcid.org/0000-0003-2770-2574

D. M. Barbano @ https://orcid.org/0000-0002-0206-7028

J. A. A. McArt ( https://orcid.org/0000-0001-5654-9172 